\title{
Synthesis, photophysical, electrochemical and thermal investigation of Triarylamines based on 9H-Xanthen-9-one: Yellow-green fluorescent materials
}

\author{
BHARAT K SHARMA, AZAM M SHAIKH and RAJESH M KAMBLE* \\ Department of Chemistry, University of Mumbai, Santacruz (East), Mumbai 400 098, India \\ e-mail: kamblerm@chem.mu.ac.in
}

MS received 14 April 2015; revised 7 September 2015; accepted 18 September 2015

\begin{abstract}
Triarylamines containing 9H-Xanthen-9-one core and aromatic units such as phenyl, naphthyl and $\mathrm{p}-$ methoxyphenyl were synthesized by employing palladium catalyzed $\mathrm{C}-\mathrm{N}$ bond forming amination reaction in good yields. The photophysical studies revealed that the absorption and emission spectra are influenced by the nature of the peripheral amines. The photoemission spectra can be readily tuned in the range 483-532 nm (solution) and 525-576 nm (film) displaying green or yellow emission (film) depending on the nature of the amine segment with optical band gaps in the range $2.52-2.75 \mathrm{eV}$ (film). The ionization potential and electron affinity were found to be in the range $5.332-5.686 \mathrm{eV}$ and $2.705-2.776 \mathrm{eV}$, respectively. Thermal studies revealed that the synthesized compounds have good thermal stability with $5 \%$ and $10 \%$ weight loss at temperature ranging from $260-330^{\circ} \mathrm{C}$ and $340-370^{\circ} \mathrm{C}$, respectively.
\end{abstract}

Keywords. Triarylamines; 9H-Xanthen-9-one; Palladium-catalyzed aryl amination; Yellow-Green florescent materials.

\section{Introduction}

Organic semiconductors have received considerable attention during the last few decades because of fundamental curiosity about their electro-optical properties and technological applications. Organic $\pi$-conjugated molecules have been explored for their application as organic light emitting diodes (OLEDs), ${ }^{1}$ organic field effect transistors (OFETs) ${ }^{2}$ and dye-sensitized solar cells. ${ }^{3}$ Since the breakthrough work by Tang and VanSlyke ${ }^{4}$ in 1987, OLEDs appear to be the display devices in future. Donor-acceptor (D-A) molecules have recently attracted considerable attention as electroluminescent multifunctional materials for OLEDs. ${ }^{5}$ Molecules containing electron-donating amino groups have been found to exhibit interesting charge-transporting properties in electroluminescent devices. ${ }^{6}$ Triarylamines-based rigid polyaromatic chromophores such as anthracene, ${ }^{7}$ fluorene, ${ }^{8}$ pyrene, ${ }^{9}$ carbazole, ${ }^{10}$ dibenzothiophene, ${ }^{11}$ etc., have been utilized in electronic devices with dual functions, i.e., hole transporting and fluorescent characteristics especially in OLEDs.

The electroluminescence (EL) from such D-A molecules can originate from locally excited states of

*For correspondence the D or A moiety, or from intramolecular charge transfer (ICT) excited states ${ }^{12}$ or even from intermolecular excimers or exciplexes. ${ }^{13}$ Thus, a judicious choice of the D/A units could allow the simultaneous control of the HOMO/LUMO levels and the emission color of the D-A molecule. EL colors spanning the visible region, including blue, ${ }^{14}$ green, ${ }^{15}$ yellow, ${ }^{16}$ and red $^{17}$ have been achieved from OLEDs based on D-A molecules.

Further, the incorporation of polyaromatic groups in the triarylamine core extends the conjugation in the molecular structure and has been found to be highly beneficial by effectively enhancing the optical properties such as absorption, emission as well as thermal stability. ${ }^{10,18}$ Additionally, the presence of bulky groups around the trigonal amine nitrogen often hinders the aggregation of molecules in the solid state. The colour of the emission in such compounds was tuned by the electronic nature of the aromatic group. For instance, the anthracene, ${ }^{7}$ fluorene, ${ }^{8}$ pyrene $^{9}$ and perylene-based ${ }^{19}$ triarylamines usually display blue emission, while the triarylamines derived from carbazole ${ }^{10}$ and fluoranthene ${ }^{20}$ emit either green or yellow photons.

However, triarylamines derived from electrondeficient units such as quinoxaline/pyrazine, ${ }^{21}$ and oxadiazole $^{22}$ exhibit balanced charge-transporting 
properties which are important for the performance of electronic devices particularly in OLEDs. Similarly, 9H-Xanthen-9-one (Xanthone), a heteroaromatic molecule contains carbonyl group due to which it has high electron affinity and also possesses planar structure due to which the molecular overlap and intermolecular electron migration occurs easily with high efficiency in solid state. ${ }^{23}$

Keeping the above mentioned donor-acceptor architecture with the benefits of functional triarylamines in mind, we report the synthesis of novel donor-acceptor compounds featuring xanthone as core unit (acceptor) and various diarylamines (donors) derived from phenyl, naphthyl and p-methoxy-phenyl groups by employing palladium-catalyzed $\mathrm{C}-\mathrm{N}$ bond forming amination reaction and their optical, electrochemical and thermal properties.

\section{Experimental}

\subsection{Materials and Methods}

2.1a Chemicals and Instruments: All the starting materials and reagents were purchased from commercial source (Sigma Aldrich and Alfa Aesar) and were used without any further treatment and purifications unless otherwise noted. The organic solvents were of HPLC and spectroscopic grade and were dried and freshly distilled using the standard procedures and handled in moisture free atmosphere.

Investigation and confirmation of chemical structures of all the synthesized materials were done using FTIR, ${ }^{1} \mathrm{H}$ NMR, ${ }^{13} \mathrm{C}$ NMR and high resolution mass spectroscopy (HRMS). ${ }^{1} \mathrm{H}$ NMR spectra and ${ }^{13} \mathrm{C}$ NMR spectra were recorded using $\mathrm{CDCl}_{3}$ on a Bruker 300 Ultrashield spectrometer with Tetramethylsilane (TMS) as internal reference at a working frequency of $300 \mathrm{MHz}$ and $75 \mathrm{MHz}$, respectively. Fourier transform infrared (FT-IR) spectra were recorded on a Perkin Elmer Frontier 91579. High resolution Mass spectrometric measurements were recorded on Tof Micromass YA-105 HR-MS system. Melting points of the products were determined by open capillary method. The thermogravimetric analysis (TGA) was performed using Perkin Elmer Pyris Diamond TG/DTA under nitrogen atmosphere.

Column chromatography was carried out using SD-Fine silica gel (60-120 mesh), eluting with $\mathrm{n}$-hexane and chloroform. The progress of reaction and the purity of the compound were checked by thin layer chromatography (TLC) on silica gel coated glass plates, in which the spots were visualized with UV light $(\lambda 254-365 \mathrm{~nm})$ and in iodine chamber. 2.1b Redox and Spectroscopic properties: Cyclic voltammetry studies were carried out on a computer controlled AUTOLAB PGSTATE 30 electrochemical analyzer equipped with USB electrochemical interface using GPES software version 4.9.005. Typically, a three electrode cell equipped with a glassy carbon working electrode, $\mathrm{Ag} / \mathrm{AgCl}$ (non-aqueous) reference electrode and platinum $(\mathrm{Pt})$ wire as counter electrode was employed. The measurements were carried at room temperature in anhydrous acetonitrile with tetrabutyl ammonium hexafluorophosphate solution $(0.1 \mathrm{M})$ as supporting electrolyte at a scan rate of $100 \mathrm{mVs}^{-1}$. The potential of $\mathrm{Ag} / \mathrm{AgCl}$ reference electrode was calibrated by using ferrocene/ferrocenium redox couple whose known oxidation potential is $+4.8 \mathrm{eV}$.

The HOMO energy values were estimated from the peak potentials $\left(\mathrm{E}_{\mathrm{ox}}\right)$ of the oxidation event according to the equation (1). ${ }^{24}$

$$
\mathrm{E}_{\text {Hомо }}=-\left[E_{o x}^{\text {peak }}-\mathrm{E}_{\mathrm{ox}}\left(\mathrm{Fc} / \mathrm{Fc}^{+}\right)+4.8\right] \mathrm{eV}
$$

Where $\mathrm{E}_{\mathrm{ox}}\left(\mathrm{Fc} / \mathrm{Fc}^{+}\right)$is the peak potential of $\mathrm{Fc} / \mathrm{Fc}^{+}$ couple against the $\mathrm{Ag} / \mathrm{AgCl}$ electrode and $E_{o x}^{\text {peak }}$ is oxidation peak potential for the derivatives.

UV-Visible spectra were recorded for $10^{-5} \mathrm{M}$ toluene solutions in a $1 \mathrm{~cm}$ path length quartz cuvette and for thermally deposited thin solid films, on SHIMADZU UV-2401PC at room temperature. The excitation and emission spectra were carried out on a Perkin Elmer LS 55 Fluorescence spectrophotometer. The fluorescence quantum yields $\left(\phi_{F}\right)$ were calculated relative to $\mathrm{Alq}_{3}$ in benzene $\left(\phi_{F}=0.16\right)^{25}$ as a standard for green emitting materials.

\subsection{Synthesis of materials (2-4)}

The detailed synthetic route adopted for the synthesis of triarylamines based on xanthone $\mathbf{2 - 4}$ is depicted in scheme 1 and the molecular structures of the synthesized derivatives are illustrated in chart 1 . The starting bromo derivative, 2,7-Dibromoxanthen-9-one (1) required for the present study was synthesized according to the reported procedure ${ }^{26}$ and the bromo precursor was conveniently converted to the triarylaminated derivatives $\mathbf{2 - 4}$ by treating it with the corresponding diarylamine using palladium catalyzed Buchwald-Hartwig amination reaction ${ }^{27}$ utilizing palladium-bis(dibenzylideneacetone) $\left[\mathrm{Pd}(\mathrm{dba})_{2}\right]$ as a catalyst, 2-dicyclohexylphoshpino-2', $6^{\prime}$-dimethylbiphenyl (SPhos) as a ligand and sodium tertbutoxide as a base, under nitrogen atmosphere for 12$24 \mathrm{~h}$ at $100^{\circ} \mathrm{C}$, giving derivatives $\mathbf{2}-\mathbf{4}$ with yield more than $50 \%$. 


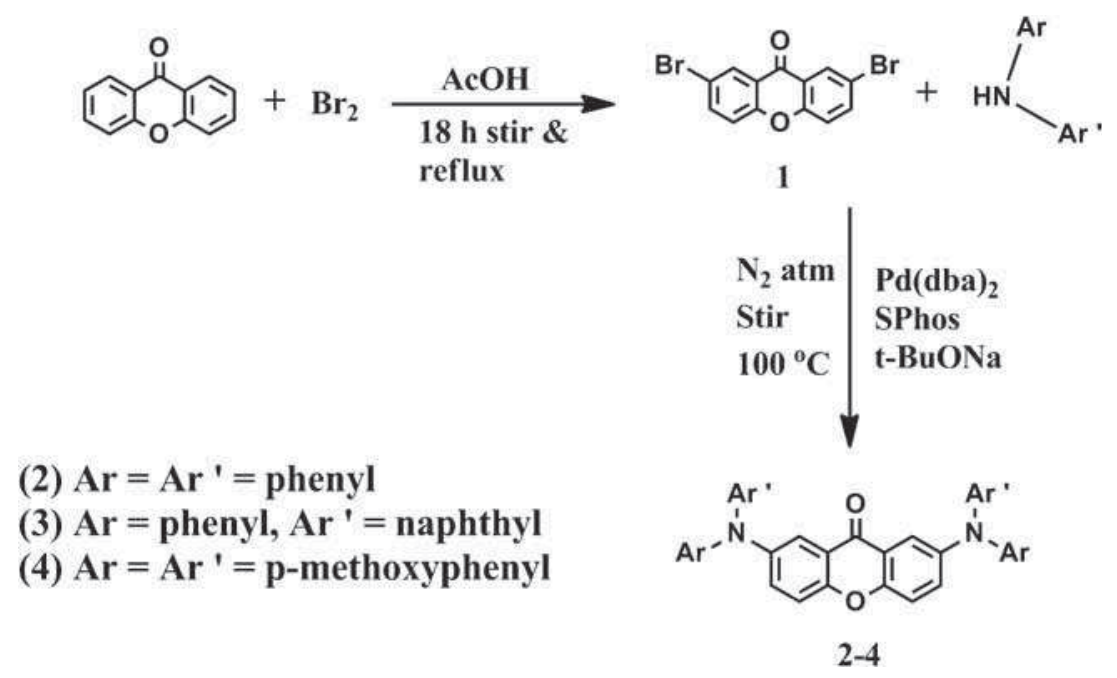

Scheme 1. Synthesis of 2-4.

The $\mathrm{C}-\mathrm{N}$ bond formation can be verified by the presence of peak at $1235-1303 \mathrm{~cm}^{-1}$ in FT-IR Spectra, corresponding to the stretching frequency of $\mathrm{C}-\mathrm{N}$ bond (figure S1, see Supporting Information). Further, the weak $\mathrm{C}-\mathrm{H}$ stretching was observed for all the molecules which may be due to the pseudosymmetry in these molecules. Substitution of xanthone with arylamine affords the corresponding triarylamine derivatives $\mathbf{2 - \mathbf { 4 }}$ as yellow to orange coloured solid soluble in common organic solvents including dichloromethane, toluene, chloroform, acetonitrile etc. However, they are sparingly soluble in alcohols and insoluble in water.

2.2a 2,7-Dibromoxanthen-9-one (1): Bromination of xanthone was done by the reported method which utilizes the following steps to get the desired product 2,7-Dibromoxanthen-9-one (1). Bromine (10 mL) was added dropwise over $20 \mathrm{~min}$ to a solution of xanthone $(5 \mathrm{~g} ; 25.5 \mathrm{mmol})$ in acetic acid $(45 \mathrm{~mL})$. The solution was stirred continuously and heated at reflux temperature for $20 \mathrm{~h}$, after which half of the solvent was removed by vacuum distillation. The reaction mixture was allowed to cool and then poured over crushed ice to obtain the off-white solid. The resulting solid was filtered and collected and washed with sodium bicarbonate to neutralize the acetic acid and further treated with $20 \%$ aqueous solution of sodium bisulfate to remove excess bromine. The obtained solid was then dried under vacuum and purified using column chromatography (eluent: $\mathrm{n}$-hexane) to afford $(6.7 \mathrm{~g}, 52.4 \%)$ pure white crystalline solid desired product (1) M.p.: $211^{\circ} \mathrm{C}$; Lit. M.p.: $211-212^{\circ} \mathrm{C}^{28}$<smiles>O=c1c2cc(N(c3ccccc3)c3ccccc3)ccc2oc2ccc(N(c3ccccc3)c3ccccc3)cc12</smiles>

2<smiles>O=c1c2cc(N(c3ccccc3)c3cccc4ccccc34)ccc2oc2ccc(N(c3ccccc3)c3cccc4ccccc34)cc12</smiles>

3<smiles>COc1ccc(N(c2ccc(OC)cc2)c2ccc3oc4ccc(N(c5ccc(OC)cc5)c5ccc(OC)cc5)cc4c(=O)c3c2)cc1</smiles>

4

Chart 1. Structure of synthesized Compounds 2-4. 
$2.2 \mathrm{~b} \quad 2,7-B i s(N-$ phenylanilino $)$ xanthen-9-one (2): A mixture of 2,7-Dibromoxanthone (1) (354 mg, $1 \mathrm{mmol}$ ) and diphenylamine $(530 \mathrm{mg}, 2 \mathrm{mmol})$ was dissolved in anhydrous toluene $(20 \mathrm{~mL})$. To this solution, palladium bis(dibenzylideneacetone) $[\mathrm{Pd}$ $(\mathrm{dba})_{2}$ ] $\left(30 \mathrm{mg}, 5.21 \times 10^{-5} \mathrm{~mol}\right), 2$-dicyclohexylphoshpino-2', 6'-dimethylbiphenyl (SPhos) (45 mg, $\left.11 \times 10^{-5} \mathrm{~mol}\right)$ and sodium tert-butoxide $(300 \mathrm{mg}$, $3.1 \mathrm{mmol}$ ) were added. The reaction mixture was continuously stirred under nitrogen atmosphere at $100^{\circ} \mathrm{C}$ for $12 \mathrm{~h}$. Reaction mixture was then cooled to room temperature and extracted with chloroform. The solid thus obtained was then purified by column chromatography (eluent: $n$-hexane: chloroform ratio as 80:20) to obtain a bright yellow solid. Yield: $63.4 \%$; M.p.: $173^{\circ} \mathrm{C}$; IR (KBr) v/cm ${ }^{-1} 1264$ (C-N str), 1654 $(\mathrm{C}=\mathrm{O}$ str $), 1073$ ( $-\mathrm{O}-\mathrm{str})$; HR-MS $\mathrm{m} / \mathrm{z}$ calcd for $\left[\mathrm{M}^{+}\right] \mathrm{C}_{37} \mathrm{H}_{27} \mathrm{~N}_{2} \mathrm{O}_{2}$ 531.2073; found $m / z$ : 531.2071; ${ }^{1} \mathrm{H}$ NMR $\left(300 \mathrm{MHz}, \mathrm{CDCl}_{3}, \delta, \mathrm{ppm}\right): 6.998-7.093$ (m, 12H, ArH) 7.219-7.394 (m, 8H, ArH), 7.465 (d, $\left.2 \mathrm{H}, J_{1}=2.7 \mathrm{~Hz}\right), 7.495\left(\mathrm{~d}, 2 \mathrm{H}, J_{1}=2.7 \mathrm{~Hz}\right) 7.96$ $(\mathrm{d}, 2 \mathrm{H}, J=2.7 \mathrm{~Hz}) ;{ }^{13} \mathrm{C}$ NMR $\left(75 \mathrm{MHz}, \mathrm{CDCl}_{3}, \delta\right.$, ppm): 119.00, 120.07, 122.16, 123.17, 124.06, 129.45, 131.66, 144.11, 147.48, 152, 176.27; Anal. Calcd. (\%) For $\mathrm{C}_{37} \mathrm{H}_{27} \mathrm{~N}_{2} \mathrm{O}_{2}$ : C-83.59, H-5.11, N-5.27; Found (\%): C-83.64, H-5.15, N-5.18.

2.2c Synthesis of 2,7-Bis(N-naphthylanilino)xanthen -9-one (3): A mixture of 2,7-Dibromoxanthone (354 mg, $1 \mathrm{mmol}$ ) and $\mathrm{N}$-naphthylphenylamine $(530 \mathrm{mg}$, $2 \mathrm{mmol}$ ) was dissolved in anhydrous toluene $(20 \mathrm{~mL})$. To this solution, palladium bis(dibenzylideneacetone) $\left[\mathrm{Pd}(\mathrm{dba})_{2}\right]\left(30 \mathrm{mg}, 5.21 \times 10^{-5} \mathrm{~mol}\right), 2$-dicyclohexylphoshpino-2', 6'-dimethylbiphenyl (SPhos) (45 mg, $\left.11 \times 10^{-5} \mathrm{~mol}\right)$ and sodium tert-butoxide $(300 \mathrm{mg}$, $3.1 \mathrm{mmol}$ ) were added. The reaction mixture was continuously stirred under nitrogen atmosphere at $100^{\circ} \mathrm{C}$ for $24 \mathrm{~h}$. Reaction mixture was then cooled to room temperature and extracted with chloroform. The solid thus obtained was then purified by column chromatography (eluent: $\mathrm{n}$-hexane: chloroform ratio as 80:20) to obtain a bright yellow solid. Yield: $340 \mathrm{mg}, 54.0 \%$; M.p.: $265^{\circ} \mathrm{C}$; IR (KBr) v/cm ${ }^{-1} 1303$ (C- N str), 1648 ( $\mathrm{C}=\mathrm{O}$ str), 1143 (-O- str); HR-MS $\mathrm{m} / \mathrm{z}$ calcd for $\left[\mathrm{M}^{+}\right] \mathrm{C}_{45} \mathrm{H}_{31} \mathrm{~N}_{2} \mathrm{O}_{2}$ 631.2386; found $\mathrm{m} / z$ : 631.2402. ${ }^{1} \mathrm{H}$ NMR $\left(300 \mathrm{MHz}, \mathrm{CDCl}_{3}, \delta, \mathrm{ppm}\right): 6.91-7.016(\mathrm{~m}$, 10H, ArH,), 7.145-7.399 (m, 14H, ArH) 7.760 (d, 2H, $J=8.1 \mathrm{~Hz}), 7.863(\mathrm{~d} 2 \mathrm{H}, J=9.3 \mathrm{~Hz}, \mathrm{ArH})$, $(\mathrm{d}, 2 \mathrm{H}, J=8.4 \mathrm{~Hz}, \mathrm{ArH}) ;{ }^{13} \mathrm{C}$ NMR $\left(75 \mathrm{MHz}, \mathrm{CDCl}_{3}\right.$, $\delta$, ppm) 117.35, 118.85, 121.59, 121.94, 122.10, $123.97,126.20,126.35,126.50,126.80,127.16$, $128.51,129.29,129.62,130.96,135.38,143.06$,
144.67, 148.18, 151.48, 176.43. Anal. For $\mathrm{C}_{45} \mathrm{H}_{31} \mathrm{~N}_{2} \mathrm{O}_{2}$, Calcd.(\%): C-85.55, H-4.94, N-4.43; Found (\%): C-85.58, H-4.88, N-4.47.

2.2d Synthesis of 2,7-Bis(4,4' -methoxydiphenylamine) xanthen-9-one (4): A mixture of 2,7- $\mathrm{Di}$ bromoxanthone $(354 \mathrm{mg}, 1 \mathrm{mmol})$ and 4,4'methoxydiphenyl amine $(530 \mathrm{mg}, 2 \mathrm{mmol})$ was dissolved in anhydrous toluene $(20 \mathrm{~mL})$. To this solution, palladiumbis (dibenzylideneacetone) $\left[\mathrm{Pd}(\mathrm{dba})_{2}\right](30 \mathrm{mg}$, $\left.6 \times 10^{-5} \mathrm{~mol}\right), 2$-dicyclohexylphoshpino-2', 6'-dimethylbiphenyl (SPhos) $\left(45 \mathrm{mg}, 11 \times 10^{-5} \mathrm{~mol}\right)$ and sodium tert-butoxide $(300 \mathrm{mg}, 3.1 \mathrm{mmol})$ were added. The reaction mixture was continuously stirred under nitrogen atmosphere at $100^{\circ} \mathrm{C}$ for $16 \mathrm{~h}$. Reaction mixture was then cooled to room temperature and extracted with chloroform. The solid thus obtained was then purified by column chromatography (eluent: $n$-hexane: chloroform ratio as 80:20) to obtain a bright orange solid. Yield: $338 \mathrm{mg}, 52.16 \%$; M.p.: $195^{\circ} \mathrm{C}$. IR (KBr) $v / \mathrm{cm}^{-1} 1235(\mathrm{C}-\mathrm{N}$ str $), 1656(\mathrm{C}=\mathrm{O}$ str $), 1035(-$ $\mathrm{O}-$ str); HR-MS $m / z$ calcd for $\left[\mathrm{M}^{+}\right] \mathrm{C}_{41} \mathrm{H}_{35} \mathrm{~N}_{2} \mathrm{O}_{6}$ 651.2495; found $m / z: 651.2474 ;{ }^{1} \mathrm{H}$ NMR $(300 \mathrm{MHz}$, $\left.\mathrm{CDCl}_{3}, \delta, \mathrm{ppm}\right): 3.768\left(\mathrm{~s}, 12 \mathrm{H},-\mathrm{OCH}_{3}\right), 6.810(\mathrm{~d}$, $8 \mathrm{H}, J=9.0 \mathrm{~Hz}, \mathrm{ArH}), 7.024(\mathrm{~d}, 8 \mathrm{H}, J=8.7 \mathrm{~Hz}$, $\mathrm{ArH}), 7.245$ (d, 2H, $J=2.7 \mathrm{~Hz}, \mathrm{ArH},), 7.326(\mathrm{~d}, 2 \mathrm{H}$, $J=2.7 \mathrm{~Hz} \mathrm{ArH}), 7.356(\mathrm{~d}, 2 \mathrm{H}, J=2.7 \mathrm{~Hz}, \mathrm{ArH}$,$) ;$ ${ }^{13} \mathrm{C}$ NMR (75 MHz, $\left.\mathrm{CDCl}_{3}, \delta, \mathrm{ppm}\right): 55.466,114.47$, $114.89,116.11,118.558,121.858,124.16,126.12$, 128.86, 140.78, 144.96, 150.95, 155.96, 176.41; Anal. For $\mathrm{C}_{41} \mathrm{H}_{35} \mathrm{~N}_{2} \mathrm{O}_{6}$ Calcd. (\%): C-75.55, H-5.41, N-4.29; Found (\%): C-75.59, H-5.44, N-4.23.

\section{Results and Discussion}

\subsection{Photophysical properties}

In order to realize the functioning of organic materials in device applications, studying their photophysical properties is important. The photophysical properties of the synthesized molecules are greatly influenced by the nature of peripheral amines. The photophysical studies were performed on the $10^{-5} \mathrm{M}$ solution of $\mathbf{2 - 4}$ in various solvents as well as thin solid film using UVVis absorption and fluorescence spectroscopy. The pertinent data are summarized in table 1 and table S1 (see Supporting Information) and the spectra are displayed in figures 1 and 2.

The synthesized molecules show similar UV-Vis absorption spectra in solution and thin solid film (figure 1). However, parent molecule xanthone shows two absorption peaks at 285 and $338 \mathrm{~nm}$ arising due to 
Table 1. Photophysical data of the synthesized compounds 2-4.

\begin{tabular}{|c|c|c|c|c|c|c|c|c|c|}
\hline \multirow[b]{2}{*}{ Compounds } & \multicolumn{5}{|c|}{ Toluene } & \multicolumn{4}{|c|}{ Thin Film } \\
\hline & $\begin{array}{c}\lambda_{\max }{ }^{\mathrm{a}}, / \mathrm{nm} \\
\left(\varepsilon_{\max } / \mathrm{M}^{-1} \mathrm{~cm}^{-1} \times 10^{3}\right)^{\mathrm{b}}\end{array}$ & $\begin{array}{c}\lambda_{\mathrm{em}}^{\mathrm{c}} \\
/ \mathrm{nm}\end{array}$ & $\begin{array}{l}\text { Stokes } \\
\text { shift }^{\mathrm{d}} \text {, } \\
/ \mathrm{cm}^{-1}\end{array}$ & $\begin{array}{l}E_{g}^{o p t ~ \mathrm{e}} \\
/ \mathrm{eV}\end{array}$ & $\phi_{\mathrm{F}}^{\mathrm{f}}$ & $\lambda_{\max }^{\mathrm{a}}, / \mathrm{nm}$ & $\begin{array}{c}\lambda_{\mathrm{em}}^{\mathrm{c}} \\
/ \mathrm{nm}\end{array}$ & $\begin{array}{l}\text { Stokes } \\
\text { shift }^{\mathrm{d}}, \\
/ \mathrm{cm}^{-1}\end{array}$ & $\begin{array}{c}E_{g}^{o p t e} \\
/ \mathrm{eV}\end{array}$ \\
\hline 2 & $\begin{array}{c}306(99.93), 327(107.47) \\
400(10.42)\end{array}$ & 493 & 4716 & 2.71 & 0.14 & $307,328,413$ & 527 & 5237 & 2.52 \\
\hline 3 & $\begin{array}{l}286(55.80), 318(68.39) \\
352(28.06), 398(10.03)\end{array}$ & 483 & 4421 & 2.75 & 0.22 & $265,318,357,413$ & 525 & 5165 & 2.75 \\
\hline 4 & $\begin{array}{c}299(74.29), 325(70.88), \\
425(7.47)\end{array}$ & 532 & 4732 & 2.56 & 0.22 & $301,328,430$ & 576 & 5894 & 2.56 \\
\hline
\end{tabular}

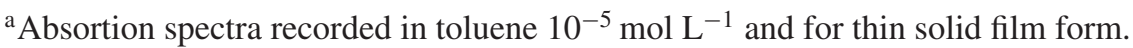

${ }^{\mathrm{b}}$ Extinction coefficient $\left(/ \mathrm{M}^{-1} \mathrm{~cm}^{-1} \times 10^{3}\right)$ measured in toluene.

${ }^{c}$ Emission spectra recorded in toluene $10^{-5} \mathrm{~mol} \mathrm{~L}^{-1}$ and for thin solid film form.

${ }^{\mathrm{d}}$ Stokes shift calculated from charge transfer absorption and emission maxima observed in solution and thin solid film form.

${ }^{\mathrm{e}}$ Optical bandgap estimated using emission and excitation spectra in toluene and thin solid film form.

$E_{g}^{o p t}=\left(1240 / \lambda_{\text {opt }}\right) \mathrm{eV} . \lambda_{\text {opt }} / \mathrm{nm}$ values are $457(2), 450(3), 484$ (4)

${ }^{\mathrm{f}}$ Quantum yield relative to $\mathrm{Alq}_{3}\left(\phi_{F}=0.16\right.$ in benzene $) .{ }^{25}$

$\pi-\pi^{*}$ and $\mathrm{n}-\pi^{*}$ transition. Upon substituting the electron donating amine groups at the $2^{\text {nd }}$ and $7^{\text {th }}$ position of xanthone, the absorption maxima are found to be blue shifted in all the derivatives. The absorption spectra of the compounds 2-4 (figure 1) exhibit a well-resolved absorption profile in the range of $286-425 \mathrm{~nm}$. Among these transitions, the higher energy absorption between $286-352 \mathrm{~nm}$ is probably originating from the $\pi-\pi^{*}$ and $\mathrm{n}-\pi^{*}$ transition located within the arylamine units and the xanthone core while the lower energy band between $398-425 \mathrm{~nm}$ is attributed to the charge transfer transition between the electron-donating diphenylamine and the electron-accepting 9H-xanthen-9-one core.

In addition, the absorption spectrum of the derivative $\mathbf{3}$ is found with a shoulder peak at $352 \mathrm{~nm}$ which may be due the $\pi-\pi^{*}$ transition overlapping with lower energy charge transfer transition (figure 1). The $\lambda_{\max }$ in absorption for all the derivatives as thin films are found to be nearly same order relative to the solution spectra.

The compounds $\mathbf{2}$ and $\mathbf{3}$ emit green light with $\lambda_{\max }$ at 493 and $483 \mathrm{~nm}$ (figure 2a) upon excitation at their corresponding absorption maxima in toluene with a bathochromic shift of $34 \mathrm{~nm}$ and $42 \mathrm{~nm}$ in thin solid film, respectively (figure 2b), while the compound 4 shows green emission with $\lambda_{\max }$ at $532 \mathrm{~nm}$ in toluene (figure $2 \mathrm{a}$ ) and a significantly $(44 \mathrm{~nm})$ red-shifted yellow emission at $\lambda_{\max } 576 \mathrm{~nm}$ as thin film due to the auxochromic effect of electron-donating $\mathrm{p}-$ methoxy groups at phenyl rings of amine (figure $2 b$ ). The emission peaks of the dyes 2-4 in the toluene are in the range $483-532 \mathrm{~nm}$ with a bathochromic shift as the thin film ranging from $525-576 \mathrm{~nm}$ which may be due to the intermolecular aggregations ${ }^{29}$ in the solid state (table 1).


Figure 1. UV-Vis absorption spectra of compounds 2-4 and xanthone in toluene solution (a), and thin solid film (b). 

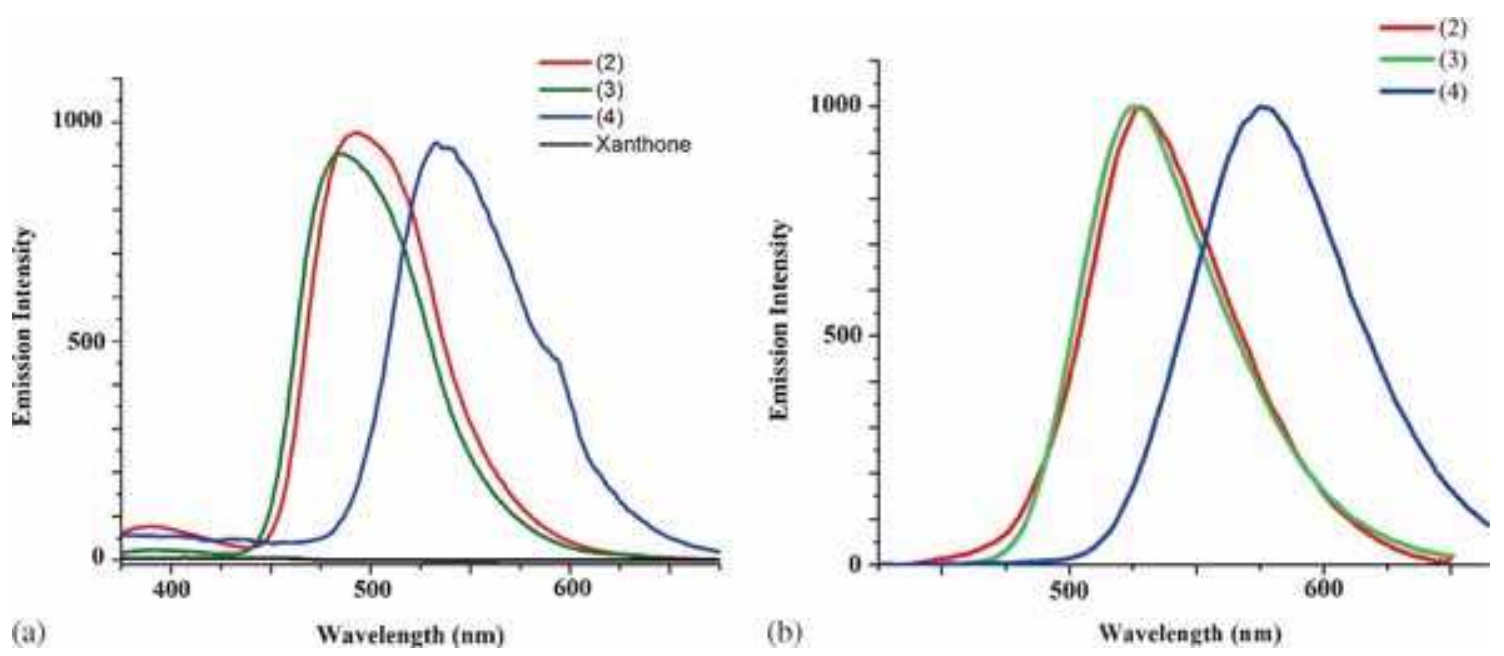

Figure 2. Emission spectra of the compounds 2-4 and xanthone in toluene solution (a), and thin solid film (b).

Further, the absorption and emission behavior of the synthesized derivatives were recorded in two other solvents, chloroform and acetonitrile (figure S5) and it was observed that the absorption spectra for all the derivatives was of the same order while the emission spectra were found to be red shifted by $36-39 \mathrm{~nm}$ for compound 2 in chloroform and acetonitrile and $43 \mathrm{~nm}$ for compound $\mathbf{3}$ in chloroform $30 \mathrm{~nm}$ blue shift for compound $\mathbf{3}$ in acetonitrile was observed as compared with the emission of the dyes in toluene. The emission intensity of the derivative 4 was quenched in polar solvents like chloroform and acetonitrile (table S1). The shifts only in the emission spectra with change in polarity of the solvent indicate that the ground state geometry of the derivatives is not affected by the polarity of solvent however excited state geometry of the compounds is greatly affected by the nature and polarity of the solvent.

Optical band gap $\left(E_{g}^{o p t}\right)$ for the derivatives in toluene and thin film were calculated using emission and excitation spectra (figure S7) and are in the range $2.56-2.75 \mathrm{eV}$ and $2.52-2.75 \mathrm{eV}$ respectively (table 1 ).
Molar extinction coefficients $(\varepsilon)$ of $\mathbf{2 - 4}$ are high in solution which indicate that the long wavelength band in the absorption spectra is a charge transfer band through the $\pi-\pi^{*}$ transition.

The Stokes shifts of molecules 2-4 were high, $4421-4732 \mathrm{~cm}^{-1}$ in toluene and $5165-5894 \mathrm{~cm}^{-1}$ in thin films ensuring that there is no re-absorption of the emitted radiation. The fluorescence quantum yield of 2-4 were calculated using tris(8-hydroxyquinolinato) aluminium(III) $\left(\mathrm{Alq}_{3}\right)\left(\phi_{F}=0.16 \text { in benzene }\right)^{25}$ as standard. The quantum yields of the derivatives are in the range 0.14-0.22 in toluene (table 1) (for chloroform and acetonitrile see table S1 in Supporting Information). Material performance of the synthesized molecules 2-4 for electroluminescent application is evaluated by Commission International de I'Eclairage (CIE) coordinates. The (CIE) coordinates of compound 2-4 are determined by using photoluminescence spectra in thin solid film. The obtained CIE are located in yellow-green region (see Supporting Information).

Table 2. Electrochemical and thermal data for compounds 2-4.

\begin{tabular}{lcccccccc}
\hline Compound & $E_{\text {ox }}^{\text {peak a }}(\mathrm{V})$ & $E_{\text {red }}^{\text {peak } b}(\mathrm{~V})$ & $\mathrm{HOMO}^{\mathrm{c}}$ & $\mathrm{LUMO}^{\mathrm{d}}$ & $\mathrm{E}_{\mathrm{g}}^{\mathrm{cv}}$ & $\mathrm{T}_{\mathrm{d}}\left({ }^{\circ} \mathrm{C}\right)^{\mathrm{f}}$ & $\mathrm{T}_{\max }\left({ }^{\circ} \mathrm{C}\right)^{\mathrm{g}}$ & $\mathrm{T}_{\mathrm{m}}\left({ }^{\circ} \mathrm{C}\right)^{\mathrm{h}}$ \\
\hline $\mathbf{2}$ & 1.218 & -1.658 & -5.686 & -2.724 & 2.962 & $280(340)$ & 410 & 173 \\
$\mathbf{3}$ & 1.129 & -1.677 & -5.597 & -2.705 & 2.892 & $330(360)$ & 450 & 265 \\
$\mathbf{4}$ & $0.864(1.315)$ & -1.612 & -5.332 & -2.776 & 2.556 & $260(370)$ & 563 & 195 \\
\hline
\end{tabular}

${ }^{\mathrm{a}} E_{\text {ox }}^{\text {peak }}$ oxidation peak potential $\mathrm{Vs} \mathrm{Fc} / \mathrm{Fc}^{+}$.

${ }^{\mathrm{b}} E_{\text {red }}^{\text {peak }}$ reduction peak potential $\mathrm{Vs} \mathrm{Fc} / \mathrm{Fc}^{+}$.

${ }^{\mathrm{c}} \mathrm{HOMO}$ energy level calculated from $\mathrm{E}_{\text {HOMO }}=-\left[E_{\text {ox }}^{\text {peak }}-\mathrm{E}_{\mathrm{ox}}\left(\mathrm{Fc} / \mathrm{Fc}^{+}\right)+4.8\right] \mathrm{eV}$.

${ }^{\mathrm{d}} \mathrm{LUMO}$ energy calculated from $\mathrm{E}_{\mathrm{LUMO}}=-\left[E_{\text {rea }}^{\text {pea }}-E_{\mathrm{red}}\left(\mathrm{Fc} / \mathrm{Fc}^{+}\right)+4.8\right] \mathrm{eV}$.

${ }^{\mathrm{e}} \mathbf{E}_{\mathbf{g}}^{\mathbf{c v}}$ calculated from $\mathbf{E}_{\mathbf{g}}^{\mathbf{c v}}=(\mathrm{HOMO}-\mathrm{LUMO}) \mathrm{eV}$.

${ }^{\mathrm{f}} \mathbf{T}_{\mathbf{d}}$ Decomposition temperature at $5 \%$ and $10 \%$ (in parentheses) and weight loss derived by TGA.

${ }^{\mathrm{g}} \mathbf{T}_{\text {max }}$ Derivative weight loss

${ }^{\mathrm{h}} \mathbf{T}_{\mathbf{m}}$ Melting point. 




Figure 3. The cyclic voltammograms of compounds 2-4 measured in acetonitrile solution against ferrocenium/ferrocene, at $100 \mathrm{mV} / \mathrm{sec}$.

\subsection{Electrochemical properties}

The charge transport capability of a molecular material can be identified from its propensity to stabilize both its cation and anion. Electrochemical measurements can be used to estimate the capability of the dye to produce and stabilize the cation and anion. We studied 2-4 by cyclic voltammetric measurements using ferrocene as an internal standard to calibrate the redox potentials. The observed parameters are reported in table 2. The cyclic voltammograms are displayed in figure 3.

On anodic sweeps, no oxidation wave was observed for the parent xanthone core (see figure S8 in SI). However, irreversible wave was presented by all of the dyes due the oxidation processes at relatively low oxidation potentials at $1.129-1.315 \mathrm{~V}$. It is attributable to the oxidation of the peripheral amines ${ }^{30}$ at the $2^{\text {nd }}$ and $7^{\text {th }}$ position of xanthone core. The oxidation potentials increased in the following order $\mathbf{4}<\mathbf{3}<\mathbf{2}$. This trend is attributed to the electronic nature of the aryl

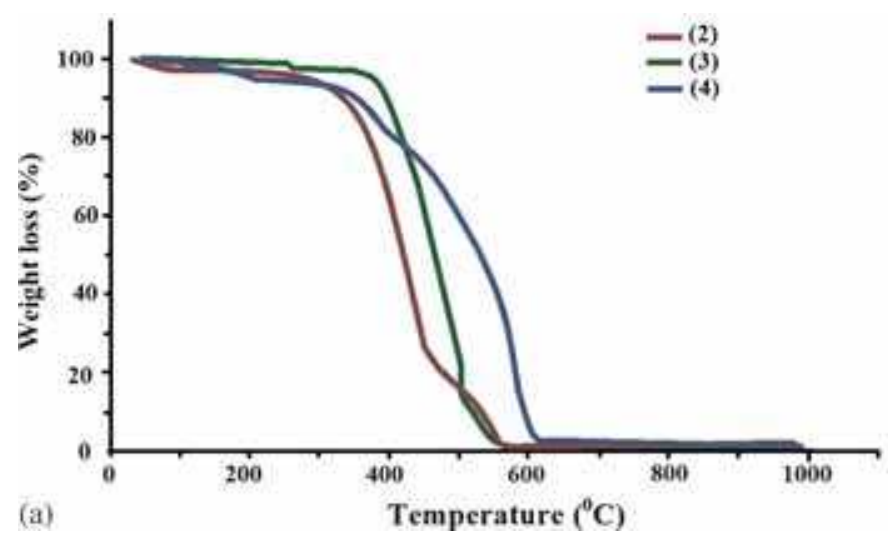

Figure 4. TGA thermograms (a) and derivative weight loss pressure. Heating rate, $10^{\circ} \mathrm{C} / \mathrm{min}$. substituents attached to the amine nitrogen. An additional reversible oxidation couple at low positive potential at $0.864 \mathrm{~V}$ is also observed for compound $\mathbf{4}$ which probably may arise from the oxidation of $\mathrm{p}-$ methoxy segment. ${ }^{30}$

On cathodic sweep, parent xanthone molecule exhibits two steps of reductions (figure S8 in SI). The first quasi-reversible peak occurs at $-1.78 \mathrm{~V}$ and another irreversible reduction peak at $-2.27 \mathrm{~V}$ due to the double reduction of carbonyl group forming dianion. 2-4 show only one irreversible reduction peak between -1.612 to $-1.677 \mathrm{~V}$ at lower potential compared to xanthone due to the presence of terminal electron donor diarylamine groups thus suggesting formation of radical anion.

The HOMO energy levels of the synthesized materials 2-4 are in range of -5.332 to $-5.686 \mathrm{eV}$ which are similar to or slightly higher than that of most widely used hole transporting material 4,4'-bis(1-naphthylphenylamino)biphenyl (NPB) $(\mathrm{HOMO}=-5.20 \mathrm{eV}$ and $\mathrm{LUMO}=-2.4 \mathrm{eV})$ and thus might be beneficial for the hole-injection and transport properties. ${ }^{31}$ The LUMO energy levels are in the range of -2.705 to $-2.776 \mathrm{eV}$. The energy band gaps determined from the cyclic voltammetry measurements are in range of $2.556-2.962 \mathrm{eV}$ and are comparable with the optically calculated band gaps.

\subsection{Thermal properties}

The thermal stability of the synthesized molecules was determined by TGA and DTA in the temperature range of $30-1000^{\circ} \mathrm{C}$ at a constant heating rate of $10^{\circ} \mathrm{C} \mathrm{min}^{-1}$ under nitrogen atmosphere. The observed TGA parameters are reported in table 2 and displayed in figure 4. TGA plots of compounds $\mathbf{2 - 4}$ indicate that the derivatives have high thermal stability with the

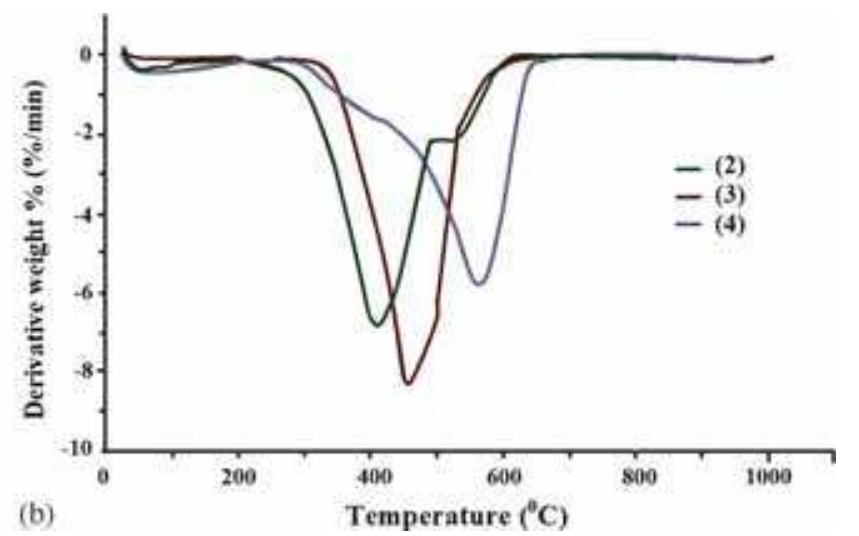

(b) of compounds 2-4 under nitrogen atmosphere at normal 
decomposition temperature corresponding 5\% and $10 \%$ weight loss in the range of $260-330^{\circ} \mathrm{C}$ and $340-370^{\circ} \mathrm{C}$ respectively (figure 4(a)) and are comparable with the previously reported hole-transporting materials such as 9,10-bis(diphenylamino) anthracene (PPA), 9,10-bis(1-napthylphenylamino)anthracene (NPA), 1,4-bis(phenyl-m-tolylamino) biphenyl (TPD), 4, 4'-bis(1-naphthylphenylamino)biphenyl (NPB) with stability in range $185-382^{\circ} \mathrm{C}^{7 \mathrm{c}, 31 \text { a }}$ The order of thermal stability among the diarylamine derivatives is $\mathbf{4}<\mathbf{2}<\mathbf{3}$ (table 2).

The derivative weight loss plot figure 4(b) shows a narrow derivative peak with high decomposition temperature with $\mathrm{T}_{\max }$ in the range of $410-563^{\circ} \mathrm{C}$ (table 2). The DTA plots of synthesized compounds 2-4 (see Supporting Information) show sharp endothermic peaks which are attributed to the corresponding melting points of compounds and exothermic peaks were observed above $350^{\circ} \mathrm{C}$ indicating that no crystallization takes place below $350^{\circ} \mathrm{C}$. Melting points of the derivatives 2-4 are in the range of $173-265^{\circ} \mathrm{C}$.

\section{Conclusions}

The triarylamines containing $9 H-$ Xanthen-9-one have been synthesized via palladium-catalyzed $\mathrm{C}-\mathrm{N}$ bond forming reaction in good yields. The compounds were thoroughly analyzed by routine spectroscopic methods and subjected to photophysical, electrochemical and thermal studies. The absorption, emission, electrochemical and thermal properties of the dyes are significantly influenced by the nature of peripheral amine segments attached to the xanthone core. The emission colour of these materials varied from green to yellow by changing the nature of the amine. The electrochemical investigation of the compounds showed that the ionization potentials and electron affinities are in a good range, comparable with the most commonly used hole-transporting materials. Thermal properties revealed that the derivatives have a high melting point and good thermal stability. The results indicate that the molecules are promising candidates for electroluminescent device applications.

\section{Supplementary Information}

All the additional details pertaining to the characterization of the compounds $\mathbf{2}-\mathbf{4}$ using FT-IR (figures S1), ${ }^{1} \mathrm{H}$ NMR (figure S2), ${ }^{13} \mathrm{C}$ NMR (figure S3), HRMS spectra (figure S4), UV-Vis absorption and emission spectra (figure S5), Absorption and Emission Properties of compound 2-4 in solvents of varying polarity and their CIE Coordinates as thin solid film (table S1), Emission and Excitation Spectra (figure S7), complete scan Cyclic Voltammograms (figure S8), Derivative weight loss and DTA plots (figure S9), CIE coordinates (figure S10) and Photograph of compounds in solution form (figure S11) are given in the Supporting Information. Supplementary Information is available at www.ias.ac. in/chemsci.

\section{Acknowledgments}

We thank the Micro-Analytical Laboratory, Department of Chemistry, University of Mumbai for providing Instrumentation facility. We also thank the Department of Chemistry IIT-Mumbai for providing HR-MS Spectra.

\section{References}

1. (a) Friend R H, Gymer R W, Holmes A B, Burroughes J H, Marks R N, Taliani C, Bradley D D C, dos Santos D A, Bredas J L, Lögdlund M and Salaneck W R 1999 Nature 397 121; (b) Baldo M A, Thompson M E and Forrest S R 2000 Nature $\mathbf{4 0 3} 750$

2. Anthony J E 2008 Angew. Chem. Int. Ed. 47452

3. (a) Imahori H, Umeyama $\mathrm{T}$ and Ito $\mathrm{S} 2009$ Acc. Chem. Res. 42 1809; (b) Ning Z and Tian H 2009 Chem. Commun. 5483; (c) Grätzel M 2009 Acc. Chem. Res. 42 1788

4. Tang C W and VanSlyke S A 1987 Appl. Phys. Lett. 51 913

5. (a) Kulkarni A P, Tonzola C J, Babel A and Jenekhe S A 2004 Chem. Mater. 16 4556; (b) Jenekhe S A, Liangde Lu and Maksudul M A 2001 Macromolecule 34 7315; (c) Furuta P T, Deng L, Garon S, Thompson M E and Frechet J M J 2004 J. Am. Chem. Soc. 126 15388; (d) Kulkarni A P, Wu P-T, Kwon T W and Jenekhe S A 2005 J. Phys. Chem. B. 109 19584; (d) Chiang C-L, Wu M-F, Dai D-C, Wen Y-S, Wang J-K and Chen C-T 2005 Adv. Funct. Mater. 15231

6. Shirota Y J J 2000 Mat. Chem. 11

7. (a) Kim S K, Yang B, Park Y I, Ma Y, Lee J-Y and Kim H-J 2009 Org. Electron. 10 822; (b) Yang B, Kim S K, Xu H, Park Y-I, Zhang H-Y, Gu C, Shen F Z, Wang C L, Liu D D, Liu X D, Hanif M, Tang S, Li W J, Li F, Shen J C, Park J W and Ma Y-G 2008 Chem. Phys. Chem. 9 2601; (c) Yu M X, Duan J P, Lin C H, Cheng C H and Tao Y T 2002 Chem. Mater. 14 3958; (d) Danel K, Huang T-H, Lin J T, Tao Y-T and Chuen C-H 2002 Chem. Mater. 143860

8. (a) Noine K, Pu Y-J, Nakayama and Kido K-I 2010 Org. Electron. 11 717; (b) Kwon Y S, Lee K H, Young K G, Seo J H, Kim Y K and Yoont S S 2009 J. Nanosci. Nanotechnol. 9 7056; (c) Jiang Z, Liu Z, Yang C, Zhong C, Qin J, Yu G and Liu Y 2009 Adv. Funct. Mater. 19 987; (d) Lai M Y, Chen C H, Huang W S, Lin J T, Ke T H, Chen L Y, Tsai M H and Wu C C 2008 Angew. Chem. Int. Ed. 47581 
9. (a) Thomas K R J, Velusamy M Lin J T, Chuen C H and Tao Y T 2005 J. Mater. Chem. 15 4453; (b) Jia W-L McCormick T, Q-D, Liu H, Fukutani M, Motala R-Y, Wang Y, Tao S and Wang 2004 J. Mater. Chem. 143344

10. (a) Shen J-Y Yang X-L, Huang T-H, Lin J T, Ke T-H, Chen L-Y, Wu C-C and Yeh M-C 2007 Adv. Funct. Mater. 17 983; (b) Thomas K R J, Velusamy M, Lin J C T, Chuen C H and Tao Y T 2004 Adv. Mater. 14387

11. Haung T-H, Lin J T, Chen L-Y and Wu C-C 2006 Adv. Mater. 18602

12. (a) Grabowski Z R, Rotkiewicz K and Rettig W 2003 Chem. Rev. 103 3899; (b) Yoshihara T, Druzhinin S I and Zachariasse K A 2004 J. Am. Chem. Soc. 126 8535

13. (a) Förster T 1969 Angew. Chem. Intl. Ed. 8 333; (b) Jenekhe S A and Osaheni J A 1994 Science 265765

14. (a) Hamada Y, Adachi C, Tsutsui T and Saito S J 1992 J. Appl. Phys. 31 1812; (b) Goes M, Verhoeven J W, Hofstraat $\mathrm{H}$ and Brunner K 2003 ChemPhysChem 4349

15. (a) Thomas K R J, Lin J T, Tao Y-T and Chuen C-H 2002 Chem. Mater. 14 3852; (b) Zhu W, Hu M, Yao R and Tian H 2003 J. Photochem. Photobiol. A 154169

16. Kelnhofer K, Knorr A, Tak Y-H and Bassler H 1997 J. Daub. Acta Polym. 48188

17. (a) Thomas K R J, Lin J T, Velusamy M, Tao Y-T and Chuen C-H 2004 Adv. Funct. Mater. 14 83; (b) Chiang C-L, Wu M-F, Dai D-C, Wen Y-S, Wang J-K and Chen C-T 2005 Adv. Funct. Mater. 15231

18. Kapoor N and Thomas K R J 2010 New J. Chem. 34 2739

19. (a) Shen W-J, Dodda R, Wu C-C, Wu F-I, Liu T-H, Chen H-H, Chen C-H and Shu C-F 2004 Chem. Mater. 16 930; (b) Wu C C, Lin Y T, Chiang H H, Cho T Y, Chen C W, Wong K T, Liao Y L, Lee G H and Peng S M 2002 Appl. Phys. Lett. 81577

20. Xia Z Y, Su J H, Fan H H, Cheah K W, Tian H and Che C H 2010 J. Phys. Chem. C 11411602

21. Thomas K R J, Lin J T, Tao Y-T and Chuen C-H 2005 Chem. Mater. 171860

22. Thomas K R J, Lin J T, Tao Y T and Chuen C-H 2004 Chem. Mater. 165437

23. Horiuchi T, Kamatani J, Yamada N, Kishino K and Saitoh A Japanese Patent WO 2011/136156 A1

24. (a) Agarawal N, Nayak P K and Periasamy N 2008 J. Chem. Sci. 120 355; (b) Shaikh A M, Sharma B K and Kamble R M 2015 Can. Chem. Trans. 3158

25. Katsuta S 1994 Chem. Lett. 1239

26. Coleman M P and Mary K B 2002 J. Org. Chem. 67 7641

27. (a) Patt P F J and Hartwig J F 1994 J. Am. Chem. Soc. 116 5969; (b) Guran A S and Buchwald S L 1994 J. Am. Chem. Soc. 116 7901; (c) Hartwig J F, Shelgy Q and Kataoka N Japanese Patent WO 02/11883 A1

28. Faust J A and Sahyun M US Patent. 1962/3,042,674

29. (a) Ulla H, Garudachari B, Satyanarayan M N, Umesh G and Isloor A M 2014 Optical Materials 36 704; (b) Jandke M, Stohriegl P, Berleb S, Werner E and Brutting W 1998 Macromolecules 316434

30. Chiu K Y, Su T X, Li J H, Lin T-H, Liou G-S and Cheng S-H 2005 J. Electroanal. Chem. 57595

31. (a) Wu C, Djurovich P I and Thompson M E 2009 Adv. Func. Mater. 19 3157; (b) Koene B E, Loy D E and Thompson M E 1998 Chem. Mater. 10 2235 